\title{
Solid-state physics resurgent
}

\section{A conference in California last week may have failed to explain superconductivity of the new kind, but it is none the less important on that account.}

Would this be another great occasion, with special sessions carrying on into the small hours, like the much-remembered meeting in New York last March of the American Physical Society? One veteran of that occasion told of having lined up outside the closed doors an hour and a half ahead of time, and of having gone home weakly, soon after midnight, long before the special session on ceramic superconductivity ended.

Comparisons with Woodstock (something to do with modern music) are apt; there have been many pop-concerts since that time in the early 1960 s, but no repetition of the first occasion. How could there be, when there is only one discovery to celebrate?

Even so, last week's meeting, technically an international workshop of new mechanisms of superconductivity, was a grand occasion. It had begun life with a discreet invitation to fourteen people to gather for an exchange of views and speculations, and had ended up filling the largest hall of the hotel which, while still within the city limits, is the furthest away from the campus that has put this Californian town on the map. More than that, the meeting had the three people who have given their names to the conventional $\mathrm{BCS}$ theory of superconductivity - Bardeen (John Bardeen, from the University of Illinois at ChampaignUrbana), Cooper (Larry R. Cooper, now at the US Office of Naval Research) and (briefly) J. R. Schrieffer (something important in industry).

Delegations from elsewhere, but especially from the Soviet Union, were lionized. Although the great V. L. Ginzburg failed to materialize, his colleague Lev Gor'kov from the Lebedev Institute in Moscow did, together with five compatriots. Californians have been much surprised to discover that Russians are charming people (and that they smoke so many cigarettes).

The Japanese were also prominent, willing like the rest to speculate about new mechanisms of superconductivity, but also eager to chance their arms on how it may be possible to make wire out of ceramics. (Extrusion through hightemperature dies seems to be a favourite recipe.) Fair play, others were just as ready to guess when and how there will be some application for the ceramic superconductors, but they were listened to as carefully as were the Japanese.
One striking feature of this cosmopolitan occasion was the prevalence of foreign accents among those masquerading as representatives of US laboratories. The Soviet delegation would have sensed at least three Russian accents in the voices of speakers invited from US laboratories (but one is that of an Israeli citizen). IBM seems strong on immigrants from Britain.

Friendliness was universally conspicuous. That, by itself, is something of a phenomenon. When people say that they find meetings valuable in opening their minds to new ideas, they often mean that they have found them useful as a means of joining a different clique. But on this occasion, people went out of their way to explain that they have fellow-feeling for all their colleagues. "We are a band of brothers", said one, in public. When asked by a journalist where the discovery of ceramic superconductivity stands in relation to that of DNA, another completely missed the point by saying that solid-state physics has nothing like that cut-throat competitiveness to spoil its collective bonhomie.

The truth is that the people at the conference felt in their bones that developments in the past few months have liberated them from dullness. "Condensedmatter physics" is what, after all, it has been called. People have been inured to the pitying tolerance of those in other fields who know that the calculations that can be done are either inexact or uninteresting, and that the important problems in the field are beyond computation.

Of course, the field does encompass a few well-known phenomena of some character. Birefringence (as with calcite) is a little piece of magic, about which too many are too blasé. The superfluidity of liquid helium is another. The notion that a ring of lead or of bismuth, if cooled in liquid helium, will sustain an electrical current once set going indefinitely, say for a year or a century, would have long since seemed magical if the phenomenon had been more familiar. That the same may now be possible merely with the help of a little liquid nitrogen seemed to many at this meeting to have put solid-state physics on the map.

The general opinion, nevertheless, was that there is not yet a theory to account for what is happening in these ternary oxides (see page 14 for a more formal account). Even so, the motto of this meeting may yet turn out to be something along the lines of
"BCS is dead; long live BCS". Put crudely, on the tercentenary of Newton's Principia, the immediate objective has been to "save the appearances".

The conventional BCS theory is a largely successful proof that, in a superconducting metal, pairs of electrons near the energetic top of a conduction band will be so affected by their mutual interaction with the vibrations of the ionic lattice in which they move that they will paradoxically attract (not repel) each other, turning from pairs of fermions into bosons which can then occupy the same quantum levels and, with a little luck, form a BoseEinstein condensate with the properties of a superfluid.

Electrons are then taken, two by two, out of the conduction bands of the material and are allowed, as bosons, to sink to energy levels several electron-volts below. Since there is no Pauli exclusion principle to keep them apart in energy, their energy is merely a reflection of the external temperature. The intuitively missing ingredient is this picture is the function of the quanta of the lattice vibrations, called phonons naturally enough.

The excitons, plasmons, magnons and the like that have occupied last week's theoreticians are means of making BCS come true, but at liquid-nitrogen temperatures. Unfortunately, the attempts to calculate the problem $a b$ initio, by starting with the wave functions which are for the time being the best guesses as to how electrons are distributed in the layer structures of a curiously valence-indifferent family of oxides, were either unconvincing or hard to understand.

Meanwhile, K. Alex Müller of IBM's Zurich laboratory, whose work (published last December) first suggested that the tenary perovskite oxides might be liquid-nitrogen superconductors, has no clear account to give on how he came to that development. He tried nickel oxides first, over several years, but they did not work. Copper oxides, he says, were a natural alternative, a remark that points to one of the ingredients missing from the whole of these proceedings, the sense that chemists have of the way in which the electron affinity of different atoms affects the properties of the structures in which they are emplaced.

But it could yet be that the discovery of the ceramic superconductors is the best thing to have happened to solid-state chemistry, not physics.
John Maddox 